Original article

\title{
White wines countering the metabolic syndrome
}

\author{
Vladimir I. Mizin ${ }^{1}$, Vladimir V. Iezhov ${ }^{1}$, Nikita A. Severin ${ }^{1}$, Anatolij Ya. Yalaneckyy ${ }^{2}$ \\ ${ }^{1}$ Academic Scientific Research Institute of Physical Methods of Treatment, Medical Climatology and Rehabilitation n.a. I.M. Sechenov, Yalta, Russia \\ ${ }^{2}$ Russian National Scientific Research Institute of Viticulture and Wine-Making “Magarach” of Russian Academy of Science, Yalta, Russia
}

Received 19 January 2017, Revised 15 May 2017, Accepted 28 July 2017

(C) 2017, Mizin V.I., lezhov V.V., Severin N.A., Yalaneckyy A.Ya.

(C) 2017, Russian Open Medical Journal

Abstract: Aim is to evaluate effectiveness of white wines as a part of medical rehabilitation in arterial hypertension (AH) patients with metabolic syndrome (MS).

Material and Methods - Analysis of effectiveness of table dry white wine "Rkatsitely Alma" (RA) and liquor white wine "Madera Alma" (MA) as parts of the spa resort treatment, was carried out in group of 163 patients with AH. The comparison of wine effects was provided in groups of 60 patients with MS and 103 patients without MS. All patients received standard treatment and 60 patients additionally received white wine RA or MA. Methods of investigation included an assessment of functional state of the leading physiological systems by 20 domains of International Classification of Functioning, Disability and Health (ICF).

Results - In patients with MS in main group (with wine consumption) the domain dynamics demonstrate more beneficial changes in comparison with control group. In particular, with respect to ICF domains b2401 "Dizziness", b410 "Heart functions", b4100 "Heart rate", b4301 "Oxygen-carrying functions of the blood", b455 "Exercise tolerance functions" and b4551 "Aerobic capacity". Although ethanol and polyphenolic compounds of wine activity are comparable, their effects vary. We can see synergistic positive activity of ethanol and polyphenols in regard to 3 ICF domains (b2401 "Dizziness", b4301 "Oxygen-carrying functions of the blood" and b455 "Exercise tolerance functions"). Synergistic negative activity of ethanol and polyphenols we can see in regard to 1 ICF domain (b4303 "Clotting functions"). There is independent negative activity of polyphenols in MS patients in regards to 2 ICF domains (b420 "Blood pressure functions" and b5408 "General metabolic functions, other specified -MS"). In patients without MS independent negative activity of ethanol was observed in regard to ICF domain b420 "Blood pressure functions". In patients with MS consumption of MA induced some more beneficial effects (including ICF domains b420 "Blood pressure functions", b5408 "General metabolic functions, other specified - MS" and b540 "General metabolic functions") and some less beneficial effects (including ICF domains b2401 "Dizziness", b28010 "Pain in head and neck" and b455 "Exercise tolerance functions"), than consumption of RA. A lot of beneficial effects of syringic (lilac) acid were observed in patients with MS.

Conclusion - The moderate consumption of white wines can be recommended to AH patients with MS in a greater extent than to patients without this syndrome.

Keywords: metabolic syndrome, medical rehabilitation, white wine.

Cite as Mizin VI, lezhov VV, Severin NA, Yalaneckyy AYa. White wines countering the metabolic syndrome. Russian Open Medical Journal 2017 ; 6: e0405.

Correspondence to Vladimir I. Mizin. Address: Muchin str., 10/3, Yalta, 298613, Russia. Fax: +7 3654323073. Phone: +7 9787075330.

E-mail: yaltamizin@mail.ru

\section{Introduction}

The researches on therapeutic and prophylactic properties of wine primarily connected with its antioxidant action against reactive oxygen species (ROS), which play an important role in the development of arterial hypertension (AH) and coronary heart disease [1-4]. A large share of cardiovascular disease is $\mathrm{AH}[5,6]$. Metabolic syndrome (MS) is becoming increasingly common [2, 5, 6]. Numerous studies point to important role of wines in prevention of various cardiovascular diseases and MS [1-4]. Studies on beneficial effects of wine are held throughout the world, including the Crimean Southern coast region [7-9]. Rational arguments for the inclusion of wine in the treatment may be MS protecting effects.
The aim of the study is to evaluate effectiveness of white wines as a part of medical rehabilitation in AH patients with MS.

\section{Material and methods}

Analysis of effectiveness of white wines as part of spa resort treatment was carried out in group of 163 patients with $\mathrm{AH}$.

All stages of the study were approved by the Ethics Committee of Academic Scientific Research Institute of Physical Methods of Treatment, Medical Climatology and Rehabilitation n.a. I.M. Sechenov (Yalta, Russia). Before inclusion in the study all participants gave written informed consent. Controlled clinical study was conducted in accordance with standards of Good Clinical Practice (GCP), Good Laboratory Practice (GLP) and Good Statistic Practice (GSP). 
Table 1. Features of investigated groups at initial state of treatment

\begin{tabular}{|c|c|c|c|c|}
\hline \multirow[t]{2}{*}{ Parameters } & \multicolumn{2}{|c|}{ Patients with MS } & \multicolumn{2}{|c|}{ Patients without MS } \\
\hline & $\begin{array}{l}\text { Core group 1A } \\
\qquad(n=26)\end{array}$ & $\begin{array}{c}\text { Control group 1B } \\
(n=36)\end{array}$ & $\begin{array}{l}\text { Core group } 2 A \\
\quad(n=34)\end{array}$ & $\begin{array}{c}\text { Control group 2B } \\
(n=67)\end{array}$ \\
\hline Female sex, \% & $53.8 \pm 10.0$ & $38.9 \pm 8.2$ & $58.8 \pm 8.6$ & $53.7 \pm 6.1$ \\
\hline Age, years & $52.2 \pm 1.6$ & $51.8 \pm 1.3$ & $55.6 \pm 1.2$ & $54.2 \pm 1.1$ \\
\hline Body constitution (-1 asthenic; 0 normal; +1 hypersthenic), c.u. & $0.63 \pm 0.10^{\$}$ & $0.72 \pm 0.08^{\&}$ & $0.03 \pm 0.09^{\$}$ & $0.21 \pm 0.06^{\&}$ \\
\hline Habitual (average) ethanol consumption, $\mathrm{ml} / \mathrm{day}$ & $15.6 \pm 5.0^{\$}$ & $21.4 \pm 5.6$ & $3.4 \pm 1.8^{\$}$ & $16.8 \pm 3.5$ \\
\hline Physical activity, hour/week & $6.4 \pm 1.9^{\$}$ & $14.1 \pm 2.9^{\$}$ & $8.4 \pm 2.4^{\&}$ & $17.1 \pm 2.4^{\&}$ \\
\hline Duration of $\mathrm{AH}$, years & $7.2 \pm 1.5$ & $8.5 \pm 1.0$ & $7.7 \pm 0.7$ & $8.3 \pm 0.8$ \\
\hline $\mathrm{CHD}, \%$ & $11.5 \pm 5.9^{\$ \&}$ & $58.3 \pm 8.9^{\text {S\# }}$ & $32.4 \pm 9.9^{\&}$ & $53.7 \pm 3.9^{\#}$ \\
\hline Functional class of $\mathrm{CHD}$, value & $0.67 \pm 0.67$ & $1.24 \pm 0.19$ & $0.73 \pm 0.30$ & $1.16 \pm 0.16$ \\
\hline $\mathrm{SBP}, \mathrm{mmHg}$ & $152.4 \pm 2.8^{\$}$ & $159.4 \pm 3.3^{\&}$ & $139.7 \pm 2.7^{\$}$ & $143.5 \pm 2.4^{\&}$ \\
\hline $\mathrm{DBP}, \mathrm{mmHg}$ & $96.5 \pm 1.8^{\$}$ & $96.5 \pm 2.0$ & $89.5 \pm 1.6^{\$}$ & $86.9 \pm 1.3$ \\
\hline Glucose, g/l & $5.7 \pm 0.3$ & $6.3 \pm 0.9$ & $5.1 \pm 0.2^{s}$ & $6.1 \pm 0.3^{s}$ \\
\hline Cholesterol, $\mathrm{mmol} / \mathrm{l}$ & $6.0 \pm 0.2^{\$}$ & $6.0 \pm 0.2$ & $5.4 \pm 0.2^{\$}$ & $5.5 \pm 0.2$ \\
\hline Triacylglycerol, mmol/l & $2.8 \pm 0.5^{\$}$ & $2.4 \pm 0.2$ & $1.4 \pm 0.2^{\$ \&}$ & $2.1 \pm 0.2^{\&}$ \\
\hline Quetelet index, $\mathrm{kg} / \mathrm{m}^{2}$ & $34.1 \pm 0.6^{\$}$ & $34.9 \pm 0.8^{\&}$ & $27.8 \pm 0.7^{\$}$ & $26.8 \pm 0.3^{\&}$ \\
\hline Number of MS components, which are exceed crucial level, c.u. & $4.12 \pm 0.13^{\$}$ & $4.03 \pm 0.12^{\&}$ & $0.15 \pm 0.09^{\$}$ & $0.03 \pm 0.03^{\&}$ \\
\hline
\end{tabular}

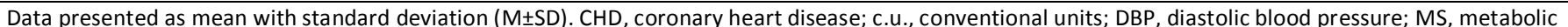
syndrome; SBP, systolic blood pressure.

$\$, \&, \#$ - statistically significant $(p<0.05)$ difference between the mean value in two groups with the same notation $\left(\right.$ between ${ }^{\$}$ and ${ }^{\$}$, between ${ }^{\&}$ and ${ }^{\&}$, between ${ }^{\#}$ and ${ }^{\#)}$.

Table 2. The white wines characteristics

\begin{tabular}{|c|c|c|}
\hline Parameters & Dry white wine "Rkatsitely Alma" & Liquor white wine "Madera Alma" \\
\hline Alcohol content, $\%$ by volume & 12.7 & 19.5 \\
\hline Sugar, mass concentration based on invert, $\mathrm{g} / \mathrm{l}$ & 0.0 & 40.0 \\
\hline Titrated acids, mass concentration in terms of tartaric acid, $\mathrm{g} / \mathrm{l}$ & 4.5 & 7.4 \\
\hline Total phenolic compounds, mass concentration, mg/l, including: & 1700.0 & 440.0 \\
\hline - Anthocyanin & 0.0 & 0.0 \\
\hline - Procyanidin & traces & traces \\
\hline - Quercetin & 0.4 & 0.0 \\
\hline - Quercetin-3-O-glycoside & 2.0 & 0.4 \\
\hline$-(+)$-D-Catechin & 42.6 & 10.6 \\
\hline - (-) Epicatechin & 16.6 & 53.3 \\
\hline - n-Coumaric acid & 1.0 & 1.6 \\
\hline - Syringic (lilac) acid & 1.4 & 2.9 \\
\hline - trans-Cautaric acid (n-coumaroil-vinous) & 13.8 & 12.4 \\
\hline - trans-Caftaric acid (caffeil-vinous) & 26.9 & 16.6 \\
\hline - Gallic acid & 59.2 & 21.9 \\
\hline - Resveratrol & 0.0 & 0.0 \\
\hline
\end{tabular}

Selection of patients with AH for the study was carried out by continuous sampling with exclusion criteria as (a) treatment duration less than 18 days, (b) allergic reaction to grape or wine, and (c) unwillingness to drink wine. The diagnosis of MS was established in presence of 1 obligate criterion of obesity (Quetelet index $\geq 30.0 \mathrm{~kg} / \mathrm{m}^{2}$ ) and 2 or more additional components: glucose level $>6.1 \mathrm{~g} / \mathrm{l}$, cholesterol level $>5.0 \mathrm{mmol} / \mathrm{l}$, triacylglycerol level $\geq 1.7 \mathrm{mmol} / \mathrm{l}$, systolic blood pressure (SBP) $\geq 130 \mathrm{mmHg}$ and diastolic blood pressure (DBP) $\geq 85 \mathrm{mmHg}$. The $38.0 \%$ of studied patients (62 persons) were suffering with MS.

The comparison of wine effect data was carried out between four groups:

i) $1 \mathrm{~A}$ core group consisted of 26 patients with MS receiving standard therapy and wine;

ii) 1B control group consisted of 36 patients with MS receiving standard treatment only (without wine reception);

iii) $2 \mathrm{~A}$ core group consisted of 34 patients without MS receiving standard therapy and wine; iv) $2 \mathrm{~B}$ control group consisted of 67 patients without MS receiving standard treatment only (without wine reception).

The main features of investigated groups are presented in Table 1.

Data distribution in all studied groups was close to normal. All patients received individual spa resort treatment, which involves the use of all necessary medical factors and pharmaceuticals (climatic- and spa-therapy, remedial gymnastics, massage, baths, physiotherapy, supporting medication, etc.). Qualitative and average quantitative characteristics of treatment program in all four groups were not significantly different (except for the wine consumption).

Main characteristics of table dry white wine "Rkatsitely Alma" (RA; produced by red or so called Kakhetian technology from white grape of Rkatsiteli variety) and liquor white wine "Madera Alma" (MA; produced by classical technology from couple of white grape of Sabbat, Sersial, Rkatsiteli, Aliquot and Pinot varieties) are presented in Table 2. 
Table 3. The ICF domain value dynamics and correlation coefficients that indicate influence of wine in AH patients with or without associated MS

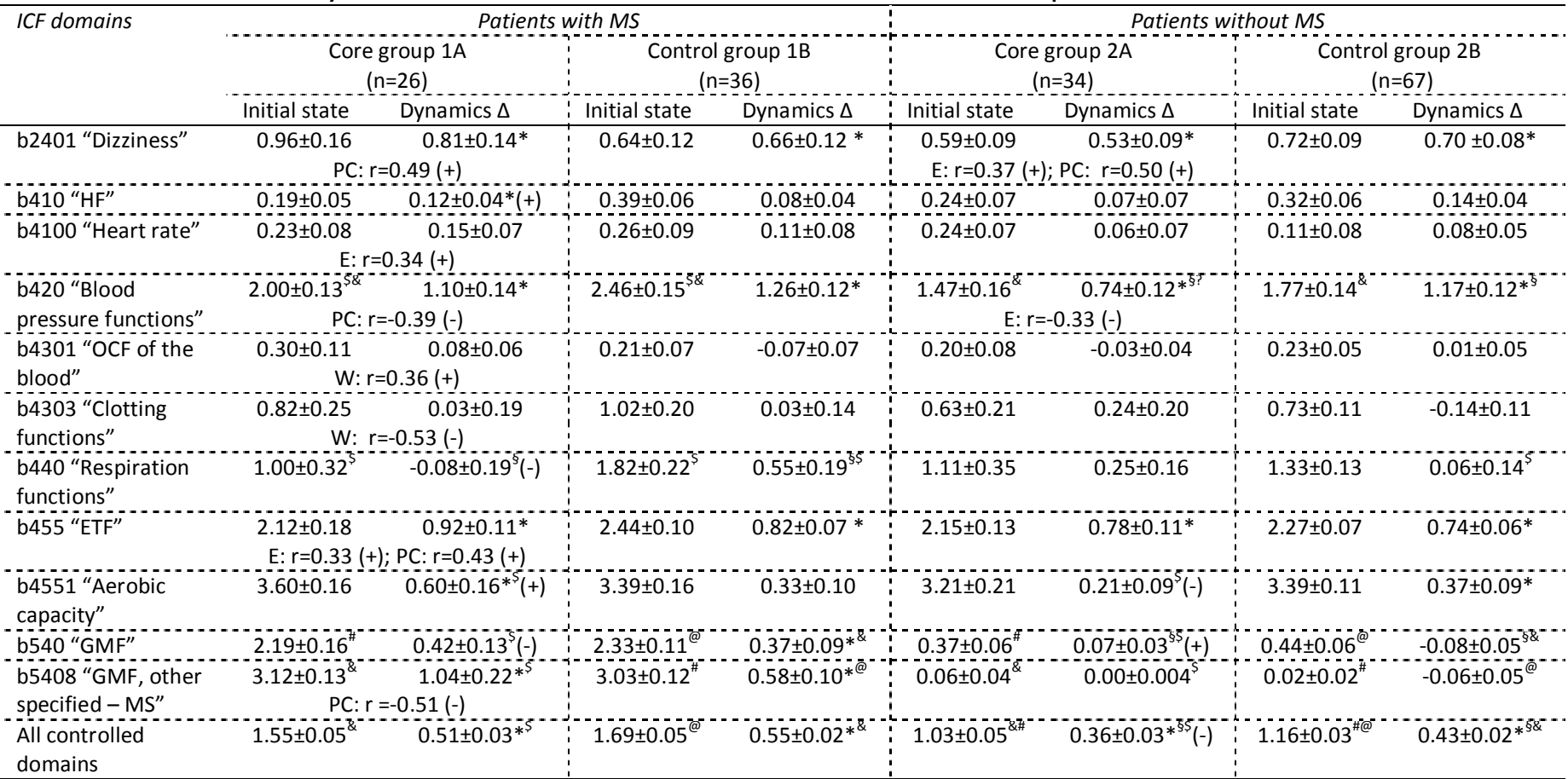

Data presented as mean with standard deviation $(\mathrm{M} \pm \mathrm{SD}) . r$, correlation coefficients with course doses of wine, ethanol and total polyphenol compounds.

ICF, International Classification of Functioning, Disability and Health; ETF, Exercise tolerance functions; GMF, General metabolic functions; HF, Heart functions; MS, metabolic syndrome; OCF, Oxygen-carrying functions.

* - statistically significant $(p<0.05)$ difference of domain values before and after treatment, i.e., significant dynamics of domain; ${ }^{\S}-$ statistically significant $(p<0.05)$ difference between the means in two groups (core and control); ${ }^{\$, ~ \&, ~ @ ~}-$ statistically significant $(p<0.050)$ difference between the means in two

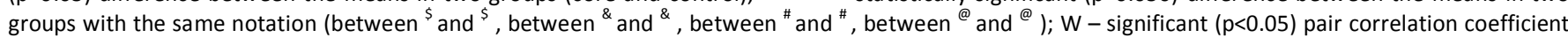
with wine course dose (drinks); $E$ - significant $(p<0.050)$ pair correlation coefficient $r$ with ethanol course dose ( $m l)$; PC - significant ( $<<0.05)$ pair correlation coefficient with total polyphenol compound course dose (mg); $(+)-$ positive (beneficial) influence of wine; $(-)-$ harmful (negative) influence of wine.

Reception of wine was carried out once a day in the afternoon. Daily doses were $250 \mathrm{ml}$ of RA (consist of $31.8 \mathrm{ml}$ of ethanol and $425.0 \mathrm{mg}$ of total phenolic compound) and $100 \mathrm{ml}$ of MA (consist of $19.5 \mathrm{ml}$ of ethanol and $44.0 \mathrm{mg}$ of total phenolic compound).

At $1 \mathrm{~A}$ core group 17 patients received RA in course dose of $3205.9 \pm 153.4 \mathrm{ml}$, taken along with $12.9 \pm 0.6$ drinks (procedures). At $1 \mathrm{~A}$ core group 9 patients received MA in course dose of $1277.8 \pm 29.4 \mathrm{ml}$, taken along with $12.8 \pm 0.3$ drinks (procedures). At $2 \mathrm{~A}$ core group 14 patients received RA in course dose of $3035.7 \pm 142.1 \mathrm{ml}$, taken along with $12.1 \pm 0.6$ drinks (procedures). At $2 \mathrm{~A}$ core group 20 patients received MA in course dose of $1385.0 \pm 57.7 \mathrm{ml}$, taken along with $13.9 \pm 0.6$ drinks (procedures).

Methods of investigation included an assessment of functional state of the leading physiological systems by 20 domains of International Classification of Functioning, Disability and Health (ICF) $[10,11]$ : b240 "Sensations associated with hearing and vestibular functions" (b2401 "Dizziness"), b280 "Sensation of pain" (including b28010 "Pain in head and neck" and b28011 "Pain in chest - heartache"), b410 "Heart functions" (including b4100 "Heart rate", b4101 "Heart rhythm" and b4103 "Blood supply to the heart"), b420 "Blood pressure functions" (including b4200 "Increased blood pressure" and b4202 "Maintenance of blood pressure"), b430 "Haematological system functions" (including b4301 "Oxygen-carrying functions of the blood" and b4303 "Clotting functions"), b435 "Immune system functions" (including b43508 "Immune response, other specified"), b440 "Respiration functions" (including b4402 "Depth of respiration"), b530 "Weight maintenance functions", b455 "Exercise tolerance functions" (including b4550 "General physical endurance", b4551 "Aerobic capacity" and b4552 "Fatigability"), b460 "Sensations associated with cardiovascular and respiratory functions", b540 "General metabolic functions" (including b5403 "Fat metabolism" and b5408 "General metabolic functions, other specified") and d240 "Handling stress and other physiological demands" (including d2408 "Handling stress and other physiological demands, other specified"). Metabolic syndrome (MS) was specified as b5408 domain.

Evaluation of the functional state was carried out using the assessment of 11 various complaints and self-assessment of common condition by the patient, objective, laboratory and functional research methods.

Objective clinical parameters included: height $(\mathrm{H})$ in centimeters, body mass (BM) in kilograms, SBP, DBP, pulse blood pressure (PBP) and heart rate (HR).

Laboratory parameters included: red blood cells (RBC), hemoglobin $(\mathrm{Hb})$, color index, erythrocyte sedimentation rate, white blood cells (WBC), basophils, eosinophils, neutrophils, monocytes, lymphocytes, activity of blood aspartic transaminase (AST) and alanine transaminase (ALT), blood prothrombin index, content of bilirubin, uric acid, fibrinogen, glucose, total cholesterol, beta-lipoprotein (BL) and triacylglycerol in blood. 


\begin{tabular}{|c|c|c|c|c|}
\hline \multirow[t]{2}{*}{ ICF domains and other parameters } & \multicolumn{2}{|c|}{ Patients with MS } & \multicolumn{2}{|c|}{ Patients without MS } \\
\hline & $\begin{array}{c}\text { Group of MA } \\
\qquad(n=9)\end{array}$ & $\begin{array}{l}\text { Group of RA } \\
\quad(n=17)\end{array}$ & $\begin{array}{c}\text { Group of MA } \\
(n=20)\end{array}$ & $\begin{array}{c}\text { Group of RA } \\
(n=14)\end{array}$ \\
\hline b2401 "Dizziness", points & $1.12 \pm 0.15^{* 5}$ & $0.22 \pm 0.15^{* 5}$ & $0.30 \pm 0.11^{* \&}$ & $0.86 \pm 0.10^{* \&}$ \\
\hline b28010 "Pain in head and neck", points & $1.11 \pm 0.11 *^{\$}$ & $1.47 \pm 0.13^{*} \$$ & $1.30 \pm 0.18^{* \&}$ & $1.00 \pm 0.15^{* \&}$ \\
\hline b420 "Blood pressure functions", points & $1.56 \pm 0.23 * \$$ & $0.84 \pm 0.14^{* \$}$ & $0.90 \pm 0.16^{*}$ & $0.50 \pm 0.18$ \\
\hline b455 "Exercise tolerance functions", points & $0.54 \pm 0.11^{\$}$ & $1.12 \pm 0.13^{* \$}$ & $0.65 \pm 0.12 *$ & $0.96 \pm 0.19 *$ \\
\hline b540 "General metabolic functions", points & $0.89 \pm 0.23 *^{\$}$ & $0.18 \pm 0.14^{\$}$ & $0.05 \pm 0.03$ & $0.11 \pm 0.06$ \\
\hline b5408 "General metabolic functions, other specified - MS", points & $2.00 \pm 0.29 *^{\$}$ & $0.53 \pm 0.21 *^{\$}$ & $0.00 \pm 0.00$ & $0.00 \pm 0.00$ \\
\hline d2408 "Handling stress and other physiological demands, other specified", points & $0.00 \pm 0.17$ & $0.33 \pm 0.26$ & $0.28 \pm 0.14^{\&}$ & $0.00 \pm 0.00^{\&}$ \\
\hline Desire to drink wine, $\%$ & $77.8 \pm 14.7^{\$}$ & $25.0 \pm 16.4^{\$}$ & $90.0 \pm 6.9^{\&}$ & $22.2 \pm 14.7^{\&}$ \\
\hline Desire to drink spirits, \% & $77.8 \pm 14.7^{\$}$ & $00.0 \pm 00.0^{\$}$ & $85.0 \pm 8.2^{\&}$ & $00.0 \pm 00.0^{\&}$ \\
\hline
\end{tabular}

ICF, International Classification of Functioning, Disability and Health; MS, metabolic syndrome.

Data presented as mean with standard deviation $(\mathrm{M} \pm \mathrm{SD})$. Effect of studied white wines presented as dynamics values of ICF domains.

* - statistically significant $\left(p<0.05\right.$ ) difference of dynamics values before and after treatment, i.e., significant dynamics; ${ }^{\$, \&}-$ statistically significant ( $<<0.05$ ) difference between the means in two groups with the same notation (between $\$$ and ${ }^{\$}$, between ${ }^{\text {, }}$ and $^{\text {\& }}$ ).

Functional parameters included:

i) electrocardiogram (ECG),

ii) Quetelet index (QI) calculated as $\mathrm{QI}=\mathrm{BM} /(0.01 * \mathrm{H})^{2}$,

iii) Robinson index (RI) - double product calculated as $\mathrm{RI}=(\mathrm{SBP} * \mathrm{HR}) / 100$,

iv) duration of Terrenkur route test,

v) vegetative index $(\mathrm{VI})$ calculated as $\mathrm{VI}=(1-\mathrm{DBP} / \mathrm{HR}) * 100$ [12],

vi) test for duration of breath holding at exhalation (BHE),

vii) stroke volume (SV),

viii) minute volume of blood (MV),

ix) total peripheral vascular resistance (TVR),

x) heart muscle power (HP),

xi) red blood cells oxygen transporting power (RBP).

All the objective, laboratory and functional investigations were conducted by standard procedures.

The estimation of the ICF domain values was carried out according to the procedure [13].

All studies were performed twice, with fixation of the results at time before treatment and after it. Mathematical analysis was performed using a standard Microsoft software (Excel Windows XP 2000), including the variation statistics and correlation analysis. Results are represented by the means and standard deviations $(\mathrm{M} \pm \mathrm{SD})$. At the same time, we also evaluated domain value dynamics $\Delta$ as: $\Delta=$ (domain value at initial state of treatment) (domain value at the end of treatment). When evaluating effects of wines, we had analyzed influence of course dose of wine (drinks), ethanol ( $\mathrm{ml}$ ) and total phenolic compounds (mg). Influence of wine was assessed as positive (beneficial) if it helped to normalize or optimize domain. The impact of wine was estimated as harmful (negative), if it increased domain deviation from the normal or optimal level. Sufficient significance of mean's difference was estimated at $p<0.05$. The same level of significance is considered as sufficient for pair correlation coefficient ( $r$ ).

\section{Results}

The statistical nature of data distribution was close to normal in all groups of patients. Taking into account the objectives of study we are presenting here the differences in functional state of patients with $\mathrm{AH}$ that are applied due to influence of white wines.
The mean values of many domains had the similar positive trend in all groups of patients under influence of performed treatment. Therefore, numerous changes in mean values of domain did not give a full assessment of wine effects, so we will not show all data obtained but that indicate wine influence. For a more detailed analysis of wine effect a correlation analysis was performed, statistically sufficient coefficients had indicated wine influence. The combined data on domain value dynamics and correlation coefficients that indicate influence of wine are presented in Table 3.

Although ethanol and polyphenolic compounds activity are comparable, their effects vary.

We can see synergistic positive activity of ethanol and polyphenols in regard to 3 ICF domains (b2401 "Dizziness", b4301 "Oxygen-carrying functions of the blood" and b455 "Exercise tolerance functions"). Synergistic negative activity of ethanol and polyphenols we can see in regard to 1 ICF domain (b4303 "Clotting functions"). There is independent negative activity of polyphenols in MS patients in regards to 2 ICF domains (b420 "Blood pressure functions" and b5408 "General metabolic functions, other specified - MS"). In patients without MS independent negative activity of ethanol was observed in regard to domain b420 "Blood pressure functions".

There are some differences in effect of studied white wines MA and RA (see Table 4).

The consumption of MA induced following effects:

i) in patients with MS - more beneficial effects on patient's self-evaluation of health, b420 "Blood pressure functions", b5408 "General metabolic functions, other specified - MS", b540 "General metabolic functions" and desire to drink wine and spirits;

ii) in patients with MS - the less beneficial effects on b2401 "Dizziness", b28010 "Pain in head and neck" and b455 "Exercise tolerance functions";

iii) in patients without MS - more beneficial effects on b420 "Blood pressure functions", d2408 "Handling stress and other physiological demands, other specified", desire to drink wine and spirits;

iv) in patients without MS - less beneficial effects on b2401 "Dizziness".

The difference of red and white grape leads to absence of syringic (lilac) acid in red wine. So, we were interested to evaluate influence of that specific polyphenolic component of white wine, results obtained are shown in Table 5. 
Table 5. The statistically significant ( $p<0.05$ ) effects of syringic (lilac) acid in AH patients with or without MS

\begin{tabular}{|c|c|c|}
\hline \multirow[t]{2}{*}{ Parameters } & \multicolumn{2}{|c|}{$\begin{array}{c}\text { Statistically significant pair correlation } \\
\text { coefficient (r) of dynamics of parameter } \\
\text { values with course dose of syringic } \\
\text { (lilac) acid (in mg) }\end{array}$} \\
\hline & Patients with MS & $\begin{array}{c}\text { Patients without } \\
\text { MS }\end{array}$ \\
\hline L. Reeder test, arbitrary units & & $0.272(-)$ \\
\hline Dizziness, points & $0.443(+)$ & \\
\hline Fatigue, points & $-0.468(-)$ & \\
\hline Self-evaluation of health, points & $-0.286(-)$ & \\
\hline WBC, $\mathrm{g} / \mathrm{I}$ & $-0.414(-)$ & \\
\hline $\mathrm{Hb}, \mathrm{mmol} / \mathrm{l}$ & $-0.487(+)$ & \\
\hline Color index, arbitrary units & $-0.327(+)$ & \\
\hline RBP, W & $-0.624(+)$ & $-0.234(+)$ \\
\hline $\mathrm{SBP}, \mathrm{mmHg}$ & & $-0.267(-)$ \\
\hline PBP, $\mathrm{mmHg}$ & $0.179(+)$ & $-0.220(-)$ \\
\hline$M V, I$ & $-0.287(+)$ & \\
\hline $\mathrm{HR}, \min ^{-1}$ & $-0.488(-)$ & \\
\hline$H P, W)$ & $-0.287(-)$ & \\
\hline Vegetative index, arbitrary units & & $-0.261(-)$ \\
\hline $\mathrm{BHE}$, sec & & $+0.246(-)$ \\
\hline Terrenkur route test, sec & $0.506(+)$ & $+0.412(+)$ \\
\hline Glucose in blood, $\mathrm{g} / \mathrm{l}$ & $-0.833(-)$ & \\
\hline Uric acid in blood, $\mathrm{mmol} / \mathrm{l}$ & $-0.484(-)$ & \\
\hline Bilirubin in blood, $\mathrm{mmol} / \mathrm{l}$ & & $-0.251(-)$ \\
\hline AST in blood, U/I & & $-0.404(-)$ \\
\hline ALT in blood, $U / I$ & & $-0.390(-)$ \\
\hline
\end{tabular}

$r$ - statistically significant $(p<0.05)$ pair correlation coefficient with syringic (lilac) acid content in consumed wine; $(+)$ - beneficial (positive) influence; $(-)$ - harmful (negative) influence.

ALT, alanine transaminase; AST, aspartic transaminase; BHE, test for duration of breath holding at exhalation; $\mathrm{Hb}$, hemoglobin; $\mathrm{HP}$, heart muscle power; HR, heart rate; $\mathrm{PBP}$, pulse blood pressure; RBP, red blood cells oxygen transporting power; SBP, systolic blood pressure; WBC, white blood cells.

\section{Discussion}

Our data describe Crimean white wine effects on functional state of AH patients with or without MS at the first time. However, some investigations on white wine effects were previously performed [14], we can't accurately compare the effects due to the difference in the chemical composition of another white wines. Chemical characteristics of wines produced in different places or made from different varieties are not similar so the wines effects are different, too. Nevertheless, we can say that effects of Crimean white wines are close to the effects of other wines in $\mathrm{AH}$ patients.

As can be seen from the data presented, the functional state of patients with MS is significantly worse than patients without MS, which indicates the importance of correcting this syndrome in the process of medical rehabilitation.

The medical rehabilitation of all patients with $\mathrm{AH}$ in the health resort of the South Coast of Crimea is characterized by generally high efficiency, which is in agreement with the data obtained earlier on effect of the Cabernet-Sauvignon red polyphenols [15]. Reception of white wine has a different effect on functions of patients; this effect differs depending on the presence or absence of MS. We have shown that patients with MS have the better rehabilitation prognosis for a complex of controlled ICF domains. Admission of white wine worsens the overall prognosis in patients without MS, but for certain domains there is a positive effect of white wines, too. Influence of wine on functional state in core group 1A (patients with MS) demonstrated more beneficial trend than in control group 1B ( 6 beneficial effects versus 5 harmful). In core group 2A (patients without MS) we can see another picture 2 beneficial effects versus 3 harmful one.

Sensations of dizziness (domain b2401) are one of the most unpleasant consequences of $\mathrm{AH}$ for the patient and severely affect the quality of their life. The positive dynamics of this domain is an important indicator of the success of medical rehabilitation. The consumption of white wine with a high content of polyphenol compounds and ethanol positive increases dynamics of the domain b2401. Previously, the beneficial effect of resveratrol (one of the components of polyphenol compounds of red wines) on cerebral blood supply and brain function has been noted [16], but we observe similar beneficial effects for white wines that are poor in resveratrol.

Violation of blood pressure regulation (domain b420) is one of the most common causes of pain and heart function disorders (domain b410), including the pulse (domain b4100). Violations in these domains significantly reduce the adaptive capacity of patients, leading to a decrease in exercise tolerance (domain b455), performance and life expectancy. The use of white wine in patients with MS improves heart function, but in all patients reduces the positive dynamics of the domain b420. These data are in good agreement with the harmful effect of ethanol on blood pressure $[17,18]$ and the harmful effect of polyphenol compounds of red grapes in patients with coronary heart disease in combination with MS [19].

The aerobic capacity (domain b4551) and the oxygen transport function of the blood (domain b4301) are important components that form exercise tolerance (domain b455). The synergistic increase in the values of domains b4301, b455 and b4551 in patients with MS under the influence of white wine improves the rehabilitation prognosis. Data on the improvement of the domain b4301 are in good agreement with the evidence of the protective effect of polyphenols on the peroxide damage of erythrocyte membrane lipids [20]. A positive effect on oxygen transport function of blood was previously established for red wine used in treatment of patients with coronary heart disease and MS [19].

The white wine polyphenol compounds together with ethanol cause pronounced positive effect on total body oxygen supply (positive dynamics of b2401 "Dizziness" and b4301 "Oxygencarrying functions of the blood") and, consequently, on physical exercise tolerance (b455 "Exercise tolerance functions") in $\mathrm{AH}$ patients with MS. Hypertension can be stimulated not only by insufficiency of oxygen supply in local tissues, but also by a decrease in the overall level of the body oxygen supply. In the latter case, an above mentioned improvement in the body oxygen supply may be an important factor and therefore white wines have beneficial protective effect in patients with $\mathrm{AH}$. Of greatest interest is the analysis of influence of wine on severity of MS and lipid metabolism. In patients with MS, wine intake negatively affects these parameters. This influence of white wines differs somewhat from data available in literature on effect of grape polyphenols. In particular, in patients with $\mathrm{AH}$ in combination with $\mathrm{MS}$, the course dose of polyphenol compounds of the nonalcoholic concentrate of red grapes Cabernet-Sauvignon significantly reduced number of MS components that exceeded critical values [15]. Polyphenol compounds of "Cabernet" red table wine in patients with coronary heart disease and MS had a beneficial effect on cholesterol levels, but also had a harmful 
impact on DBP [19]. Red wines have a greater protective effect on hyperglycemia in experimental models of type 2 diabetes than white ones, due to the different content of catechins $[8,21]$. Clinical data on the normalization of the profile of blood lipids under the influence of red wine are also given $[22,23]$, while dealcoholized red wine had no less positive effect [24, 25]. In epidemiological studies it has been established that wine consumption was associated with lower prevalence odds ratio of MS [17]. Individuals who drank moderate amounts (three to five glasses per day) of red wine were at substantially lower risk (risk ratio - 0.51) of cardiovascular mortality than those who never drank wine [26].

Mild to moderate alcohol consumption (15-20 ml of ethanol daily), especially wine, is associated with a lower prevalence of MS [2], but the relative contribution of wine's alcohol and polyphenol components to beneficial effects is unclear [3]. Procyanidins were identified as the principal vasoactive polyphenols in red wine, but in white wines we can identify only traces of procyanidins. Perhaps we have not found the influence of white wine on cholesterol metabolism due to low concentration of procyanidins [4] in comparison with red wine.

In our study, reception of white wine also had beneficial effect on function of metabolism, but only in patients without MS. In particular, a positive correlation of the dynamics of triacylglycerol with the course doses of wine $(r=0.39)$ and its components ethanol $(r=0.56)$ and the total polyphenol compound $(r=0.39)-$ was found. In patients without MS, there was also beneficial effect of course dose of wine on dynamics of Quetelet index $(r=0.30)$, too. Our results are in good accordance with data [14], there were no changes in serum cholesterol, low-density lipoprotein (LDL) cholesterol, triglyceride and fasting plasma glucose levels under influence of Pintes white wine consumption in patients with MS.

Our data indicate rather a prophylactic than therapeutic effect of white wine in relation to MS. It is the prophylactic effect on the development of MS components that is in good agreement with meta-analysis data indicating the predominantly preventive effect of such an important component of wine, as polyphenol compounds, on development of cardiovascular diseases [27].

Direct influence of wine depending on MS severity was also established. In core group of patients with MS, a statistically significant positive dynamics of number of MS components was at $1.12 \pm 0.26$, whereas in patients without MS, the dynamics of number of MS components in the core group was significantly lower $(0.03 \pm 0.03)$. In patients with MS pronounced positive dynamics of SBP was observed under the influence of wine $(25.15 \pm 4.99)$ in the core group $1 \mathrm{~A}$, whereas in patients without MS the dynamics of SBP in the core group $1 \mathrm{~B}$ was significantly lower $(12.21 \pm 1.86)$ than in the control group $2 B(18.72 \pm 1.97)$ and in the above mentioned core group $1 \mathrm{~A}$.

Above mentioned (see Table 4) difference in effect of RA and MA seems to be due to low doses of ethanol and polyphenolic compounds consumed with MA. For example, there is no effect of MA on short wind (breathlessness) in patients without MS while RA makes reduction of this complaint due to a big content of total polyphenols in daily and course doses. Polyphenols makes significant correlation influence on short wind, so to achieve a positive effect on this complaint daily polyphenol intake should be more than $400 \mathrm{mg}$. Such an intake provides by "Rkatsiteli Alma" produced by "red technology" and so rich in polyphenol compounds.
All the patients with $\mathrm{AH}$ have a number of common positive effects of MA, but the most valuable effect of MA is an improvement in the function of b540 "General metabolic functions", including the function b5408 "General metabolic functions, other specified-MS". This effect is apparently due to a good ratio of ethanol and polyphenol compounds, which have a corresponding oxidant and antioxidant effect and antagonistic effect on cytochrome P-450 [7-9, 28].

As seen from the Table 5 dynamics of some controlled parameters under influence of syringic (lilac) acid had more beneficial trend in group of patients with MS (8 parameters with beneficial dynamics versus 6 parameters with harmful one). In patients without MS we can see an opposite picture - dynamics had less beneficial trend (4 parameters versus 7 parameters with harmful dynamics). The increase in the content of lilac acid in white wines due to the appropriate variety of grapes or wine making technology will contribute to a great beneficial effect on the oxygen transport function of the blood and the tolerance to physical exercise in patients with $\mathrm{AH}$.

The investigated effects of white wines in patients with MS are in good accordance to beneficial reputation of Mediterranean diet rich in both red and white wine. One of specific polyphenolic components of white wine - syringic (lilac) acid - demonstrates predominantly positive effects for patients with MS, similar to effect of specific polyphenolic components of red wine procyanidins.

Our data provides further evidence to the advantages of using wines in comparison with strong alcoholic beverages that do not contain polyphenolic compounds of grapes.

\section{Conclusion}

The positive effects of polyphenols indicate that white wines consumption is more preferable than strong alcoholic beverages consumption. The moderate consumption of white wines can be recommended to hypertensive patients with metabolic syndrome in a greater extent than to patients without the syndrome. The clinical significance of these findings needs further investigation.

\section{Conflict of interest}

The authors declare no conflict of interest. This study is designed as a range of joint research work of above mentioned author's affiliation institutions and in no way was supported by any sponsors.

\section{Ethical approval}

All procedures performed in studies involving human participants were in accordance with the ethical standards of the institutional research committee and with the 1964 Helsinki declaration and its later amendments or comparable ethical standards.

\section{References}

1. Dhala NS, Temsah RM, Netticadan T. Role of oxidative stress in cardiovascular diseases. J Hypertens 2000; 18: 655-673. https://www.ncbi.nlm.nih.gov/pubmed/10872549.

2. Kleiner KD, Gold MS, Frost-Pineda K, Lenz-Brunsman B, Perri MG, Jacobs WS. Body mass index and alcohol use. J Addict Dis 2004; 23(3): 105-118. https://doi.org/10.1300/J069v23n03 08.

3. Corder R, Mullen W, Khan NQ, Marks SC, Wood EG, Carrier MJ, Crozier A. Oenology: red wine procyanidins and vascular health. Nature 2006; 444: 566-571. https://doi.org/10.1038/444566a. 
4. Dayoub O, Andriantsitohaina R, Clere N. Pleiotropic beneficial effects of epigallocatechin gallate, quercetin and delphinidin on cardiovascular diseases associated with endothelial dysfunction. Cardiovasc Hematol Agents Med Chem 2013; 11: 249-264. https://doi.org/10.2174/1871525712666140309233048.

5. Mancia G, Fagard R, Narkiewicz K, Redón J, Zanchetti A, Böhm M, et al. 2013 ESH/ESC Guidelines for the management of arterial hypertension: the Task Force for the management of arterial hypertension of the European Society of Hypertension (ESH) and of the European Society of Cardiology (ESC). J Hypertens 2013; 31(7): 1281-1357. https://doi.org/10.1097/01.hjh.0000431740.32696.cc.

6. Maksimov SA, Artamonova GV. Modeling of arterial hypertension's risk in occupational groups. Russ Open Med J 2013; 2: 0104. https://doi.org/10.15275/rusomj.2013.0104.

7. Brunner EY, Mizin VI. Grape polyphenols attenuate psychological stress. In: Proceedings of the NATO advanced research workshop on "Advanced bioactive compounds countering the effects of radiological, chemical and biological agents". G.N. Pierce, V.I. Mizin, A. Omelchenko, eds. Crimea, Ukraine, May 15-17, 2012. Dordrecht: Springer, 2013: 229-240.

8. Hnatush AR, Drel VR, Hanay NO, Yalaneckyy AY, Mizin VI, Sybirna NO. The protective effects of natural polyphenolic complexes of grape wine on organisms exposed to oxydative and nitrosative stress under diabetes mellitus. In: Proceedings of the NATO advanced research workshop on "Advanced bioactive compounds countering the effects of radiological, chemical and biological agents". G.N. Pierce, V.I. Mizin, A. Omelchenko, eds. Crimea, Ukraine, May 15-17, 2012. Dordrecht: Springer, 2013: 145-162.

9. lezhov VV, Mizin VI, Yalanetskyy AY. Bioactive compounds of Crimean wines countering the stress experienced by the personnel. In: Proceedings of the NATO advanced research workshop on "Advanced bioactive compounds countering the effects of radiological, chemical and biological agents". Crimea, Ukraine, May 15-17, 2012. G.N. Pierce, V.I. Mizin, A. Omelchenko, eds. Dordrecht: Springer, 2013: 271-276.

10. International Classification of Functioning, Disability and Health: ICF. Geneva: World Health Organization; 2001. https://www.who.int/classifications/icf/en

11. ICF Checklist Version 2.1a, Clinician Form. World Health Organization, 2003. https://www.who.int/classifications/icf/icfchecklist.pdf

12. Kérdö I. Ein aus Daten der Blutzirkulation kalkulierter Index zur Beurteilung der vegetativen Tonuslage. Acta Neurovegetativa 1966; 29(2): S250-S268. https://doi.org/10.1007/BF01269900.

13. Mizin VI, Severin NA, Dudchenko LS, Ezhov VV, Ivaschenko AS, Beliaeva $\mathrm{SN}$, et al. Methodology of evaluation of rehabilitation potency and efficacy under pathology of cardio-respiratory system in accordance to International Classification of Functioning, Disability and Health. Trudy Akademicheskiy NII Fizicheskich Metodov Lechenia, Medicinskoy Klimatologii I Reabilitacii imeni I.M. Sechenova 2016; 27: 1-22. Russian.

14. Abel T, Blazovics A, Wimmer A, Beko G, Gaal B, Blazics B, et al. Effect of Pintes white wine on metabolic parameters in patients with metabolic syndrome. Orvosi Hetilap 2012; 153(22): 861-865. https://doi.org/10.1556/OH.2012.29389.

15. Severin NA. Functional activity of polyphenolic compounds of red Cabernet-Sauvignon grape variety under metabolic syndrome in patients with arterial hypertension. Trudy Akademicheskiy NII Fizicheskich Metodov Lechenia, Medicinskoy Klimatologii I Reabilitacii imeni I.M. Sechenova 2016; 27: 102-108. Russian.

16. Kennedy DO, Wightman EL, Reay JL, Lietz G, Okello EJ, Wilde A, Haskell CF. Effects of resveratrol on cerebral blood flow variables and cognitive performance in humans: a double-blind, placebo-controlled, crossover investigation. Am J Clin Nutr 2010; 91(6): 1590-1597. https://doi.org/10.3945/ajcn.2009.28641.

17. Djoussé L, Arnett DK, Eckfeldt JH, Province MA, Singer MR, Ellison RC. Alcohol consumption and metabolic syndrome: does the type of beverage matter? Obes Res 2004; 12(9): 1378-1385. https://doi.org/10.1038/oby.2004.174.
18. Cicero AFG, Colletti A. Nutraceuticals and blood pressure control: results from clinical trials and meta-analyses. High Blood Press Cardiovasc Prev 2015; 22: 203-213. https://doi.org/10.1007/s40292 015-0081-8.

19. Severin NA, Mizin VI, lezov VV. Functional activity of polyphenolic compounds of red table "Cabernet" wine under metabolic syndrome. Vestnik Fizioterapii I Kurortologii 2016; 22(1): 4-8. Russian. https://elibrary.ru/item.asp?id=27315558

20. Mikstacka R, Rimando AM, Ignatowicz E. Antioxidant effect of transresveratrol, pterostilbene, quercetin and their combinations in human erythrocytes in vivo. Plant Foods Hum Nutr 2010; 65: 57-63. https://doi.org/10.1007/s11130-010-0154-8.

21. Chennasamudram SP, Kudugunti S, Boreddy PR, Moridani MY, Vasylyeva TL. Renoprotective effects of (+)-catechin in streptozotocininduced diabetic rat model. Nutrition Research 2012; 32: 347-356. https://doi.org/10.1016/j.nutres.2012.03.015.

22. Droste DW, Iliescu C, Vaillant M, Gantenbein M, De Bremaeker N, Lieunard $C$, et al. A daily glass of red wine associated with lifestyle changes independently improves blood lipids in patients with carotid arteriosclerosis: results from a randomized controlled trial. Nutr $J$ 2013; 12(1): 147. https://doi.org/10.1186/1475-2891-12-147.

23. Chiva-Blanch G, Urpi-Sarda M, Ros E, Valderas-Martinez $P$, Casas R, Arranz $S$, et al. Effects of red wine polyphenols and alcohol on glucose metabolism and the lipid profile: a randomized clinical trial. Clin Nutr 2013; 32(2): 200-206. https://doi.org/10.1016/j.clnu.2012.08.022.

24. Chiva-Blanch G, Urpi-Sarda M, Ros E, Arranz S, Valderas-Martínez P, Casas $\mathrm{R}$, et al. Dealcoholized red wine decreases systolic and diastolic blood pressure and increases plasma nitric oxide: short communication. Circ Res 2012; 111(8): 1065-1068. https://doi.org/10.1161/CIRCRESAHA.112.275636.

25. Di Renzo L, Carraro A, Valente R, lacopino L, Colica C, De Lorenzo A Intake of red wine in different meals modulates oxidized LDL level, oxidative and inflammatory gene expression in healthy people: a randomized crossover trial. Oxid Med Cell Longev 2014; 2014: 68136818. https://doi.org/10.1155/2014/681318.

26. Gronbaek M, Deis A, Sorensen TI, Becker U, Schnohr P, Jensen G. Mortality associated with moderate intakes of wine, beer, or spirits. BMJ 1995; 310: 1165-1169. https://doi.org/10.1136/bmj.310.6988.1165.

27. Hooper L, Kroon PA, Rimm EB, Cohn JS, Harvey I, Le Cornu KA, et al. Flavonoids, flavonoid-rich foods, and cardiovascular risk: a metaanalysis of randomized controlled trials. Am J Clin Nutr 2008; 88(1): 38-50. https://www.ncbi.nlm.nih.gov/pubmed/18614722.

28. Goszcz K, Deakin SJ, Duthie GG, Stewart D, Leslie SJ, Megson IL. Antioxidants in cardiovascular therapy: panacea or false hope? Front Cardiovasc Med 2015; 2: 29-76. https://doi.org/10.3389/fcvm.2015.00029.

\section{Authors:}

Vladimir I. Mizin - MD, DSc, Assistant Professor, Deputy Director of Science, Academic Scientific Research Institute of Physical Methods of Treatment, Medical Climatology and Rehabilitation n.a. I.M. Sechenov, Yalta, Russia. http://orcid.org/0000-0001-9121-8184.

Vladimir V. lezhov - MD, DSc, Professor, Head of Physiotherapy Department, Academic Scientific Research Institute of Physical Methods of Treatment, Medical Climatology and Rehabilitation n.a. I.M. Sechenov, Yalta, Russia. http://orcid.org/0000-0002-1190-967X.

Nikita A. Severin - MD, PhD, Head of Cardiology Department, Academic Scientific Research Institute of Physical Methods of Treatment, Medical Climatology and Rehabilitation n.a. I.M. Sechenov, Yalta, Russia. http://orcid.org/0000-0002-4255-4496.

Anatolij Ya. Yalaneckyy - GE, PhD, Head of Wine Technology department, Russian National Scientific Research Institute of Viticulture and WineMaking "Magarach" of Russian Academy of Science, Yalta, Russia. http://orcid.org/0000-0003-2008-8436. 